\title{
Injury Prevention in the Classroom. You Only Get One Brain
}

Can. J. Neurol. Sci. 2009; 36: 675-676

The study by Vassilyadi et al "Evaluation of ThinkFirst for Kids Injury Prevention Curriculum for Grades 7/8" in this issue of the Journal is evidence that a curriculum approved injury prevention program delivered by classroom teachers is effective in knowledge translation. Grade 7 and 8 children in Ottawa who learned about brain and spinal cord injuries from their classroom teachers showed an improvement in knowledge of neurotrauma that persisted for at least six weeks ${ }^{1}$. The injury prevention program is entitled "Navigators" and is the latest addition to the ThinkFirst for Kids curriculum for elementary school children. Navigators had not been previously evaluated for effectiveness, and the positive results of Vassilyadi and colleagues can be added to the previous positive evaluations of other components of the ThinkFirst for Kids curriculum in $\mathrm{Canada}^{2,3}$ and the United States ${ }^{4,5}$. Even though these programs are created by teachers and other knowledgeable educators and approved by Curriculum Services Canada they must be evaluated in the schools for effectiveness. It is important for organizations that provide educational programs for schools to ensure that the material is effective. Also, school boards must ensure that material presented to their students is scientifically sound and educationally effective. The limited time and financial resources available for school-based injury prevention must be spent on programs proven to be valid and educationally effective.

Although enhancement of knowledge of neurotrauma and injury prevention measures is important, the most valuable outcome measure is a reduction in the incidence and severity of injury. Unfortunately, this measure is extremely difficult and costly to obtain because it requires longitudinal tracking of injury incidence and severity over many years through counts of emergency department visits, hospital admissions and deaths reported by coroners. In Canada, we are fortunate in having both provincial and national trauma registries that provide such tracking through reports coordinated by the Canadian Institute for Health Information (CIHI), and there is some evidence that injuries in children and youth are declining. Although it is attractive to relate the decline to injury prevention programs such as ThinkFirst, the data must be evaluated very carefully. For example, CIHI reported in 2006 that hospital admissions for head injuries in children and youth up to and including 19 yearsof-age declined between 1994 and 20046 . Unfortunately, the decline in admissions may not reflect a true reduction in the incidence of head injury but merely fewer hospital admissions. A negative CT scan is now an accepted indication for discharge from the emergency department of a concussed, but otherwise neurologically intact child. Prior to the widespread availability of CT scans these children would have been hospitalized for observation. More focused epidemiological studies are required to determine the true incidence of neurotrauma and the effectiveness of injury prevention programs ${ }^{7}$. Fortunately, some of these studies do show a decline in the incidence of neurotrauma such as spinal cord injuries in ice hockey that can be attributed to injury prevention measures such as rules changes and enforcement ${ }^{8}$. Conversely, in spite of injury prevention efforts, there has been an increase in brain and spinal cord injuries in alpine skiing and snowboarding that may relate not only to changes in participation rates but also to the prevalence of risk taking behavior such as jumping and other aerial activity ${ }^{9}$.

Classrooms are an important venue for teaching injury prevention, but classroom lessons have to be reinforced by community action. Children can learn in the classroom why it is important to wear helmets while bicycling, but on the road their parents and communities need to confirm that this is the best practice. Unhelmeted parents cycling beside their children are not only risking their own brains, but also the brains of their children. Communities without bicycle helmet regulations are risking their citizens' brains, and those with the regulations but no enforcement are also taking unnecessary risks. Thus, injury prevention efforts must be multifaceted and comprehensive to be maximally effective.

In Canada, there are some great examples of community actions in injury prevention. Fort McMurray and the Regional Municipality of Wood Buffalo became the first to establish "Safe Sledding Guidelines" for its tobogganers, and the City of Vaughan was the first to create a Recreational Sports Safety Task Force to advise about safety including helmet use in specific sports and recreation and the designation of safe hills for tobogganing. At the provincial level, many governments are now active in all aspects of injury prevention, whereas previously only transport and workplace were on their injury prevention agendas. For example, the new Ontario Ministry of Health Promotion has all aspects of injury prevention as designated activities. Federally, the new Public Health Agency of Canada also has a broad, coordinating mandate for injury prevention. Indeed, Dr. Barry Pless, one of Canada's esteemed experts in childhood injury prevention, advises that it is essential for central governments to play a major role in coordinating injury prevention efforts ${ }^{10}$. Many corporations are also contributing significantly to injury prevention not only among their employees, but also for the general public through donations to injury prevention non governmental organizations such as ThinkFirst. Thus, in Canada, injury prevention is now beginning to receive the attention it deserves.

Globally, there are also injury prevention activities including the World Health Organization where it has been recognized that the incidence, type and severity of trauma has changed drastically with industrialization and development ${ }^{11}$. In general, development brings more motor vehicle crashes and more childhood and youth injuries. In 2008, the World Health Organization and the United Nations Children's Fund published 
the first World report on child injury prevention ${ }^{12}$. The report focused on the five leading causes of child injury deaths - road traffic injuries, drowning, poisoning, burns and falls, and outlined prevention strategies.

There are those who decry all these "Nanny State" activities, but how many times did your mother tell you to look both ways before crossing the street? You only get one brain!

\section{DeClaration}

I wish to declare a conflict of interest because I am the Founder of the ThinkFirst charity that developed the materials tested in the classroom by the authors of the study (Vassilyadi et al) about which I commented in the Editorial.

ThinkFirst is a registered charity in Canada which conducts injury prevention programs in schools and in the community at large, specifically designed to reduce the incidence of catastrophic injuries, such as brain and spinal cord injuries.

I have never received any financial compensation or other considerations from this organization, and continue as a volunteer, as does the author of the paper to be published in this Journal, Dr. Michael Vassilyadi.

\section{REFERENCES}

1. Vassilyadi M, Duquette C, Shamji MF, Orders S, Dagenais, S, Evaluation of ThinkFirst for Kids injury prevention curriculum for Grades 7/8. Can J Neurol Sci. 2009;36:761-8.

2. Cusimano MD, Sharman AR, Chipman M, Freedman B, Tator CH. Injury prevention in the community: an evaluation of the Think First for Kids program. Can J Neurol Sci. 2000;27:22.

3. Wesner ML. An evaluation of Think First Saskatchewan: a head and spinal cord injury prevention program. Can J Public Health. 2003;94:115-20.

4. Gresham LS, Zirkle DL, Tolchin S, Jones C, Maroufi A, Miranda J. Partnering for injury prevention: evaluation of a curriculumbased intervention program among elementary school children. $\mathrm{J}$ Pediatr Nurs. 2001;16:79-87.

5. Greene A, Barnett P, Crossen J, Sexton G, Ruzicka P, Neuwelt E. Evaluation of the ThinkFirst for Kids injury prevention curriculum for primary students. Inj Prev. 2002;8:257-8.

6. CIHI. Head injuries in Canada: A decade of change (1994-5 to 2003-4). Ottawa: Canadian Institute for Health Information; 2006.

7. Provvidenza C, Tator C. Sports injuries prevention: general principles. In: Tator $\mathrm{CH}$, editor. Catastrophic injuries in sports and recreation, causes and prevention: a Canadian study. Toronto: University of Toronto Press; 2008. p. 58-78.

8. Tator CH, Provvidenza CF, Lapczak L, Carson J, Raymond D. Spinal injuries in Canadian ice hockey: documentation of injuries sustained from 1943-1999. Can J Neurol Sci. 2004;31: 460-6.

9. Ackery A, Hagel BE, Provvidenza C, Tator CH. An international review of head and spinal cord injuries in alpine skiing and snowboarding. Inj Prev. 2007;13:368-75.

10. Pless IB. Three basic convictions: a recipe for preventing child injuries. Bull World Health Organ. 2009;87:395-8.

11. Harvey A, Towner E, Peden M, Soori H, Bartolomeos K. Injury prevention and the attainment of child and adolescent health. Bull World Health Organ. 2009;87:390-4.

12. World report on child injury prevention. Geneva: World Health Organization \& United Nations Children's Fund; 2008. 